\title{
ComplexTrans - global land transportation system The best way ahead for railways and roads is coherent cooperation, not the competition
}

DOI: $10.46932 /$ sfjdv2n1-024

Received in: November 1st, 2020

Accepted in: December 30th, 2020

\author{
Jiri Hofman \\ Engineer of Machinery \\ Institution: University of West Bohemia \\ Address: Czech Republic, 30100 Pilsen, Univerzitni 8 \\ E-mail: hofman.ji@gmail.com \\ Roman Cermak \\ Engineer of Machinery, Ph. D. \\ Institution: University of West Bohemia \\ Address: Czech Republic, 30100 Pilsen, Univerzitni 8 \\ E-mail: rcermak@kks.zcu.cz
}

\begin{abstract}
The land-transportation cannot meet its demands anymore. Jammed highways and cities, dangerous emissions, omnipresent traffic accidents, delays, expensive railways.

Solutions are being sought to transfer a large part of passenger- and especially freight-traffic to (highspeed) rail and the efforts are shifting towards electromobility, car-sharing, 5G-connectivity, autonomous ride, MaaS-transport-coordination or Hyperloop-type solutions.

However, all these solutions have further problems and limitations.

Solutions are not sought where they really exist - in the mutual adaptation of the road and rail vehicles and their deep cooperation.

The ComplexTrans-project shows that simply adapting dimensions and functions of the road and rail vehicles can eliminate (or at least substantially reduce) all the problems of existing land transport. The main features of the ComplexTrans system are sufficient parking spaces, reduced traffic density inside and outside of the cities, electric-vehicles with unlimited range and cheaper than the standard cars, cheaper and affordable recharging of batteries, autonomous ride, self-financing rail-transport, transfer of intercity freight to rail, replacement of part of the continental air-transport and many others.
\end{abstract}

Keywords: TRANSPORT: Intermodal, Road - Rail, Passenger, Freight, City, Intercity, Private, Public; TRANSPORT SOLUTIONS: E-Mobility, Hydrogen Drive, Autonomous Ride, Car Parking, CarSharing, MaaS, Platooning; TRANSPORT PROPERTIES: Traffic Density, Safety, Comfort, Time Independence, Weather Independence; ENERGY AND EMISSIONS: Consumption Reduction, Independence Of Crude Oil, CO2 Reduction, Vehicle To Grid V2g, Energy Safet

\section{INTRODUCTION}

Railways and roads, the two land-based transportation systems, are competing with each other. Roads are much more successful, and railways are trying to cope with a low share of passengers and cargo by introducing more comfort, increasing speeds and making other innovations. However, there is a 
significant development in road mobility and it is not easy for railways to keep up. Cooperation between road and railway systems is limited.

Can railways be as successful as roads?

ComplexTrans is a research project which has been running for more than 25 years. It is based on the mutual adaptation of road and railway vehicles and on the cooperation between both systems to create a global intra- and inter-city transport system for passengers and goods, to react to current transportation problems and to offer completely new possibilities in transport and related non-transport issues.

\subsection{CURRENT STATUS OF ROAD AND RAILWAY TRANSPORTATION IN THE EU}

With growing populations, industrialization and globalization the requirements for transportation of people and goods are increasing.

Road and railway transportation are two of the most common means of surface transport. The road transport accounts for the majority of passenger transport (83\% individual $+9 \%$ mass transport) and transport of goods (75\%), while the railway transport of people and goods is significantly lower (8\% and $18 \%$ respectively).1) As a result the railways are not financially self-supporting and need significant assistance from public funds.

Below are the main causes of this trend:

- the automobiles (and partially also trucks) provide door-to-door transport without transfer or reloading,

- are completely independent of time,

- offer privacy

- and only fuel costs of automobile transportation (for private personal transport) are usually taken into account and other costs (depreciation and maintenance) are not considered.

Trains offer many advantages as well:

- $\quad$ higher maximum and traveling speed

- low specific energy consumption

- electrical drives and relative independence from fossil fuels

- higher operational safety

- lower dependence on weather conditions (fog, snow, ice). 
The high transport capacity of railways is very important as it allows the reduction of the load on crowded roads. This is one of the main reasons why the EU member states support railways and strive to move more people and goods onto rails.

\subsection{SEPARATE DEVELOPMENT OF ROAD AND RAILWAY TRANSPORT}

There is currently an extensive development in the railway industry, which includes interoperability, increasing

comfort and speed of passenger transport, dense and comfortable suburban transport of passengers and expanded and improved transportation of goods.

Furthermore, focused is on interoperability, easy maintenance, increasing safety, and reduction of costs.

Road transport is also developing.

- The most significant research topics are:

- electrical and hydrogen drives (or synthetic fuels) to replace crude oil products

- autonomous driving (driverless vehicles)

- connectivity and information sharing through 5G networks

- car-sharing.

What do these developments in road transport mean for railways?

With electric or hydrogen drives (or synthetic fuels) in cars, one of the advantages of railways will disappear. Such drives will mean road transport is not dependent on crude oil and is more ecological, the same as electric trains. However, for this to happen the batteries need to become lighter and cheaper.

Furthermore, car batteries could be used for storing spare energy produced by solar and wind power which can be an important contribution to a sustainable energy management system. Unfortunately, this cannot be offered by railways.

Autonomous driving promises higher safety, and spare time for drivers which can be used more effectively. The same can be offered by trains, but with the lack of privacy and without door-to-door transport.

Autonomous driving includes connectivity for increased safety; so the crew has uninterrupted internet access during the journey.

It is expected that connectivity and autonomous driving will increase the capacity of roads. But this idea is not completely compatible with safety standards so far. 
High quality autonomous driving will require more time for research and many issues still must be solved (e.g. driving in bad weather conditions, legal responsibility, terrorism, etc.), but it will come sooner or later sure.

Car sharing should guarantee that the demanding and expensive technologies mentioned above will be publicly available. With car sharing one can have lower costs, modern technologies, and will never need to look for a parking place. Privacy will be possible, but partially limited. It will be necessary to plan your trips. And it might be cheaper and more comfortable for frequent travellers to have their own vehicles.

The role of autonomy in the transport of goods is even more important. Transport costs will decrease without the need for drivers. But there is one more question - how will the driverless vehicles be protected against robbery? Will a thief be able to stand in front of an autonomous truck, stop it, secure it against movement, and then steal its cargo?

Another problem is the battery, which needs higher capacity and power for transporting goods. There are several solutions being tested with above-the-ground power supplies (eHighway2)), or installed into the road with electromagnetic contactless transfer to the vehicle (Primove3)), which use is limited by insufficient precision in maintaining the short distances necessary for energy transfer.

When these problems have been solved, the differences between roads and railways will further increase in favour of roads.

To be able to compete with the roads of the future, railways must become more efficient. How can we do this?

The current trend in rail passenger transport is to further increase the maximum speed (to over 400 $\mathrm{km} / \mathrm{h}$ ), requiring more sophisticated vehicle infrastructure and technology, and improve its accessibility. Using MaaS, passengers should be transported uncomplicated from/to the train by autonomous road vehicles. With such a service, trains can be the fastest transport for distances between $200 \mathrm{~km}$ and 800 $\mathrm{km}$. For a return trip they can be up to 3 hours faster than other means of transport (except Hyperloop).

To keep the price of train tickets affordable, trains must be used fully. Fully loaded train means higher income on the one hand and lower fare; but on the other hand less privacy and a growing distaste for travelling by trains.

Surprisingly, the development of road transport and increased related costs can have a positive influence on the increasing competitiveness of trains. Sharing autonomous cars will not be cheap, and for longer distances trains can be cheaper.

Competitiveness of long-distance bus transport can be limited by financial tools (taxes), if necessary. 
Private cars will remain competitive, but their numbers will decrease due to their high price and easy car sharing.

The main problem of railway cargo transport is that cargo trains operate at lower speeds than passenger trains and therefore they must stop at sidings to allow them to be overtaken. This fact significantly decreases their average speed. New concepts for cargo trains suppose either higher speeds (up to ca. $200 \mathrm{~km} / \mathrm{h}$ ) or separate the cargo from the passenger transport by track or by time.

It takes a long time to insert a cargo carriage into a cargo train and to move it from the final station to the customer. Therefore new concepts are being sought (LastMile 4), NGT Cargo 5), CargoSprinter 6), etc.).

If customers do not have rail sidings, goods must be transshipped. In that case, a container transport 7) might be more effective, especially with roll-away containers (Abroll-) 8), but they are efficient only for longer distances.

In any case, it is difficult to achieve the same competitiveness of railway transport with roads. On the one hand it is expected that railways will come up with new concepts which will overtake road transport and attract new passengers and goods. On the other hand, road transport is also introducing new concepts which make it even more attractive.

The main advantages of road transport (door-to-door, time independency and privacy during the journey) cannot be achieved by railways without additional measures.

\subsection{COOPERATION BETWEEN ROAD AND RAILWAY TRANSPORT - CURRENT STATUS}

Surprisingly, "driverless cars with electric propulsion" have been in operation in Europe for more than 60 years. They are personal cars and trucks which are transported by trains (car-trains for personal cars 9) and RoLa10) trains for trucks). The driver does not need to drive the car during the journey and even does not need to be transported with lorry.

The majority of such trains are electric. The transport is organized similar to MaaS.

Unfortunately, the number of such trains is relatively low and there is no tendency to growth. On the contrary, the number of car-trains is decreasing. What is the reason?

The main reason is a low profitability. And one more reason. Why should passengers travel with cars by special (night)train and reduce the line capacity, when they can travel without their cars by high speed trains in the day (and minimize the lost of high speed trains, which need to be subsidized)?

From this point of view it is better to reduce the number of car-trains (and also night trains).

Is it possible to counteract the trend of decreasing numbers of car- and RoLa trains and make them profitable?

To answer this question correctly, an analysis of their properties must be done. 
- It is possible to get on at point A and get off at point B only

- Distance between A and B must be sufficient long - often over $1000 \mathrm{~km}$. Only those destinations are selected where a sufficient number of customers can be expected. The number of such destinations is marginal in the overall amount of transport.

- Loading and unloading personal cars and trucks is sequential and takes a long time.

- Passengers cannot stay in their cars during the journey. It makes loading and unloading more complicated and increases the costs of the journey.

- For every kilogram of transported car, several kilos of train mass are required. It makes the energy savings lower and the costs of the transport higher

- Car-trains are rare. It limits the number of users.

- Price of transport (compared with the price of fuels for road transport) is much higher. There must be a 'really good reason' for using this kind of transport (timesaving, safety, ...).

- The use of car-trains and RoLa trains is very limited by these issues.

An exception are trains which overcome natural obstacles. These trains have only low or zero competition from road transport and are used efficiently. Such trains travel shorter distances (around 50 $\mathrm{km}$ ) several times a day and people can stay in their vehicles during the journey. 11)

The second exception are systems of intermodal transport of goods, which allow parallel loading and unloading of superstructures and their transport without the driver (e.g. Modalohr 12) or CargoBeamer 13)).

When the properties of car- and RoLa-trains are more similar to the properties of road transport, or they become even better and the prices are affordable, railways can become profitable again. Is it possible?

There are several partial unrealized projects in this respect. The first designs date back to the 1980s. Small cars for two people were to be transported on the lower floor of the double-deck rail coaches.14) In the first decade of this century, a similar project (UC) was created, but already with electric cars15). In 2018 the project one4all, which focuses on passenger and freight intermodality, was presented.16)

\section{COMPLEXTRANS - MUTUAL ADAPTATION OF ROAD AND RAIL VEHICLES AND THEIR DEEP COOPERATION - AN EFFECTIVE DEVELOPMENT VARIANT TO THE SEPARATE DEVELOPMENT OF CARS AND TRAINS}

One of the ways to significantly improve land transport, removing dependency on crude oil and creating new possibilities, is the mutual adaptation and cooperation of road and railway vehicles. 
Road and railway vehicles have been evolving independently since the beginning (200 years in the case of railways and 125 years for road vehicles). An exception is the one-sided adaptation of trains for transporting cars and trucks, which has only been a limited success. Mutual adaptation means that not only railway vehicles, but also road vehicles must take steps towards adaptation. Surprisingly, this can contribute not only to the development of cooperation, but can be also beneficial for both types of transport itselves.

This is the subject of the ComplexTrans project, which began in the early 1990s and focused on transporting cars of the usual size with passengers in the same double-deck rail coach with a possibility to be (dis)loaded in each station. In order to increase transport efficiency, new type passenger cars with extendable axles were gradually designed and freight and passenger transport modules with swiveling wheels were added. Subsequently, two-storey passenger-freight platforms, located in semi-terminals on the ends of towns and connected by shuttles, were added. Subsequently, the use of newly conceived passenger cars in urban traffic was elaborated.

How should such cooperating vehicles look? (Fig. 1)

FIG.1 - platform of the ComplexTrans system: passengers change (upper deck) and loading and disloading of adapted cars (coupemobiles) with passengers and freight modules (lower deck) in the ComplexTrans trains.

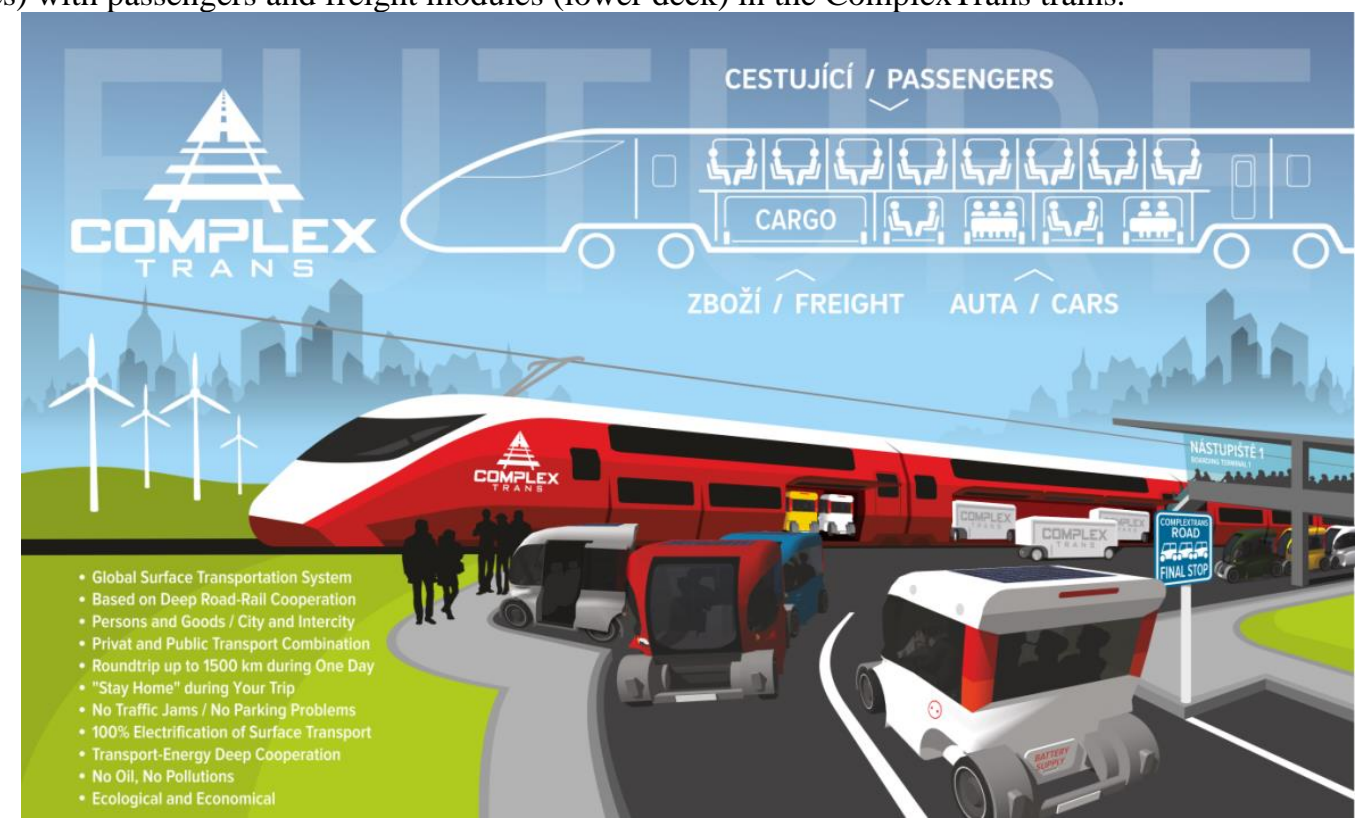

\subsection{RAILWAY VEHICLES IN THE COMPLEXTRANS SYSTEM ${ }^{17)}$}

A fundamental concept of the railway part of the ComplexTrans system is the sharing of the same train by passenger and cargo transport into one train.

ComplexTrans trains consists of two types of carriages:

- combined passenger-cargo double decker railway carriages 
- fast cargo carriages, connected at the end of the train (Fig.2)

Aside from these, a third type is considered - fast motor coaches for passengers attachable during the ride.

FIG. 2 - individual fast freight wagons or their small groups are connected and disconnected to/from the back of ComplexTrans trains with double-deck passengers-freight coaches.

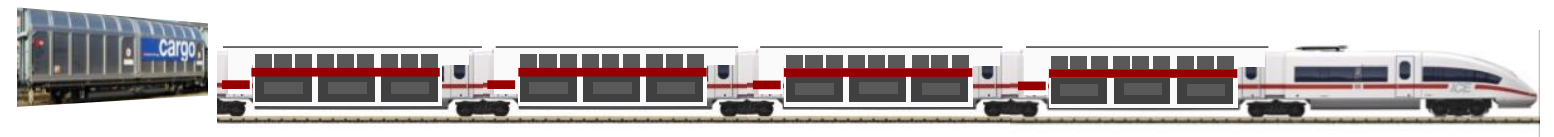

The role of fast cargo carriages remains the same as today. They can reach the speed of ComplexTrans trains and be quickly attached/detached separately or in small groups to/from the end of the train during stay in the station. No more marshalling yards, no more slow separate freight trains.

The basis of ComplexTrans trains are double-deck carriages, where passengers are transported on the upper deck, and cars with passengers and mobile passengers or goods modules are transported on the lower deck (Fig.3).

The double-deck carriages are equipped preferably with Jakob's bogies, with the boarding and exit areas equipped with tipping stairs and toilets.

There are a central isle and small compartments (with 2 or 4 seats, reconfigurable to beds) on the upper deck.

The lower deck is equipped with a large, partly glass tipping door, which allows side loading/unloading of the road vehicles from/to the platform.

FIG.3 - double-deck railway coach of the ComplexTrans system - the upper floor serves for passengers and the lower floor is used for freight transport modules and passenger cars (coupemobiles). There are boarding areas, staircases and sanitary facilities at the ends of the coach.
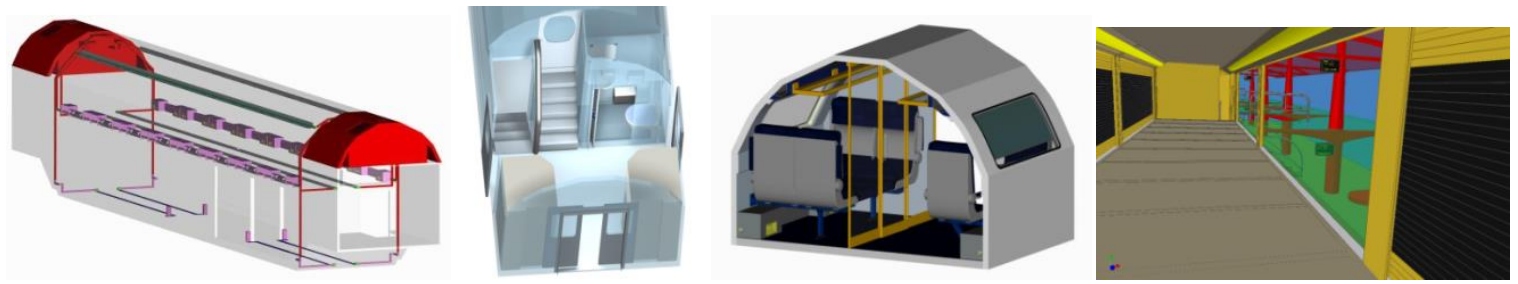

All the ComplexTrans system railway vehicles comply with profile UIC 505-1 for electrified tracks.

\section{Considering}

- that trains stop at distances approx. from 50 to $200 \mathrm{~km}$ for 3-5 minutes,

- that should be minimized energy consumption and noise

- that should be maximized the use of existing infrastructure 
- the way of use

the optimum operating speed is $200 \mathrm{~km} / \mathrm{h} \pm 20 \%$.

Maximum axle load about $20 \mathrm{t}$ is assumed.

\subsection{ROAD VEHICLES IN THE COMPLEXTRANS SYSTEM ${ }^{18)}$}

Road vehicles in the ComplexTrans system have two main functions - ride on the road from door to door and possibility of side loading, transport and side unloading on, in and off the ComplexTrans trains. Road vehicles must be able to make the whole trip only using the roads.

The internal dimensions, configuration and equipment of the vehicles will guarantee passenger comfort similar to a train compartment (a 'coupe') - from which comes the name 'coupe-mobile'. Passengers can feel at home during their journey. It also means that trains in the ComplexTrans system can be built more simply and cheaply.

There are three levels of vehicles suitable for transport on ComplexTrans trains.

\subsection{1 level 1}

The simpliest vehicles suitable for the ComplexTrans system (both passenger and cargo) must fulfill the following requirements:

- Dimensions: $\approx 4500$ (length) $\mathrm{x} \approx 2100 / 2550$ (width passenger/cargo) $\mathrm{x} \approx 1950 \mathrm{~mm}$ (height)

- Weight including the cargo up to $3.5 \mathrm{t}$

- Readiness for loading and unloading using pallets and/or handling equipment.

This level is very demanding for logistics of loading and unloading, and should be limited only in the initial phase of establishing the ComplexTrans system, and later only exceptionally.

\subsection{2 level 2}

- same dimensions and weight as Level 1

- $\quad$ equipped with wheels swiveling 90 degrees to allow side loading

- adjustable clearens 50-150 mm

- preferably with electric drive

This level allows self-loading onto ComplexTrans trains and makes the logistics easy. It is suitable especially for goods transport and specific passenger transport. 
2.2.2.1 Personal vehicles with this design are a very spacious variant of automobile, and fulfill almost all passenger requirements. Transport in ComplexTrans trains is easy possible, but often not optimal, because the costs of passenger transport are double that of Level 3 due to the dimensions.

2.2.2.2 Cargo vehicles are similar to transport containers with four wheels and can include 8 (10) Europallets (Fig. 4 - left). They have an electric drive with limited power. Remote control is used for local handling.

Outside the terminals, the cargo modules are transported separately or preferably in short sets driven by guiding vehicles, which can be also used as energy sources for the set transport.

2.2.2.3 Another type of transport module is a module for passengers (Fig. 4 - right). The module is only $\approx 2100 \mathrm{~mm}$ wide and offers space for the comfortable transport of up to 12 persons. It can be used for different special operations (e.g. for check-in during the ride for following flight, for additional services, etc.), and during the initial phase of establishing the ComplexTrans system, when adequate terminals are not yet available and lower decks of ComplexTrans trains cannot be used for goods transport.

2.2.2.4 Level 2 ComplexTrans road vehicles include also other vehicles - e.g. small four wheel vehicles (with about half the width of a coupe-mobile), guiding vehicles of platoons, and low-floor buses able to drive up to the platforms of ComplexTrans terminals.

FIG.4 - The freight and passenger transport modules are equipped with its own low power electric drive for independent local manipulation. The wheels can be swiveled $90^{\circ}$ for lateral loading into the railcoach.
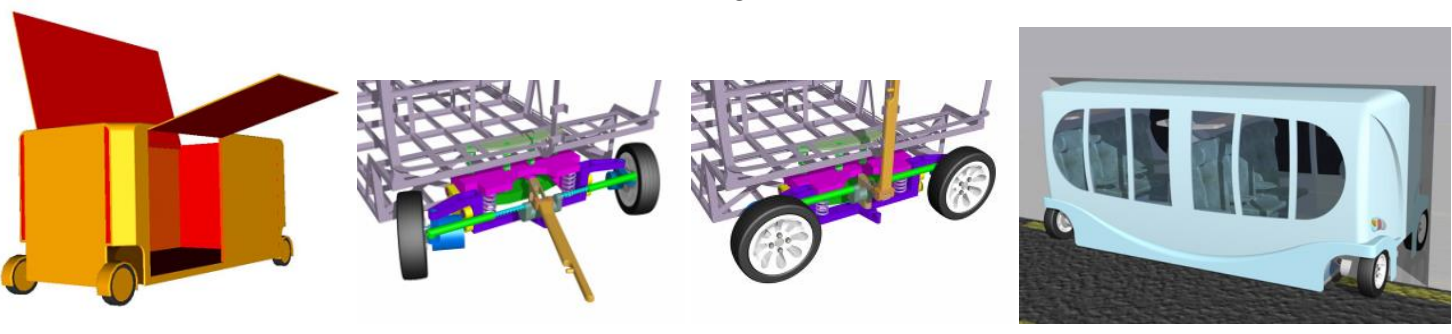

\subsection{3 level 3}

- length limited to $2200 / \approx 2600 \mathrm{~mm}$ (passenger/cargo vehicles) and width to $2000-2150 \mathrm{~mm}$, height the same as Level $1(\approx 1950 \mathrm{~mm})$

- total length of vehicles during the journey is about one meter more (with axles extended to front and back, which creates protection against impacts)

- $\quad$ maximum weight about $1750 \mathrm{~kg}$

- $\quad$ capacity 5 adults (comfortably seated) $+\approx 4001$ main luggage space above rear seats 
- adjustable clearens $5-15 \mathrm{~cm}$

- electric drive - 2 motors integrated in the rear wheels with batteries for 2 day operation in city (range ca. $200 \mathrm{~km}$ )

- maximum speed about $120 \mathrm{~km} / \mathrm{h}$ (in single driving mode) or 130-150 km/h (driving in platoon)

- other equipment

$\circ \quad$ catch points in the roof for lifting/overground transport by parking manipulators/cableways

$\circ \quad$ couplings for platooning

○ readiness for ad-hoc implementation into 'semi-public' personal transport.

2.2.3.1 Level 3 personal vehicles (coupemobiles - Fig.5) can be easily and quickly loaded onto the lower deck of ComplexTrans trains by own force. During the transport on the train the vehicle is connected to the electrical network of the train and passengers can stay inside the vehicle and enjoy the comfort and technology of the own vehicle. All train services are achievable by a side lengthways aisle. The smaller dimensions (the axles retracted) mean two coupe-mobiles can be transported instead of a standard size car, which substantially reduces energy consumption and also transportation costs to a level comparable with road transport.

With the retracted axles, the vehicle is not longer than $2.2 \mathrm{~m}$. It can also be used for parking perpendicular to the pavement, using the longitundal parking lanes. This can save half of the space necessary for parking and also time for parking maneuvers.

Other abilities of coupemobiles:

Catch points in the roof allow implementation of new ways of parking - in above and below ground parking silos, later on parking platforms above pavements, or even parking on 'balconies' of new multistorey buildings. It brings not only an increasing comfort, number of safe and guaranteed parking places, but also frequent connection and cooperation with the electricity network. It offers the possibility of using the space of a coupemobile and its equipment for non-transport purposes when parked. Catch points make also overcoming obstacles (e.g. rivers and mountains) by special cableways possible.

Readiness for mechanical/electronical coupling into platoons saves the ground space during journeys, increases the throughput of crossroads, saves energy, allows temporarily (on a voluntary basis) to include private vehicles in public transport and significantly decreases urban traffic density.

Coupemobiles are also an additional opportunity for better organizing urban and extra-urban transport.

2.2.3.2 Level 3 cargo vehicles (modules for goods transport) are $\approx 400 \mathrm{~mm}$ longer than coupemobiles $(\approx 2600 \mathrm{~mm})$ and are intended for transport of up to 3-5 europallets. As with Level 2 modules, the modules 
are equipped with electric drive with the possibility of remote control. They are not equipped with a permanent driver's space and are transported to/from the customer separately or in a platoon with a guiding vehicle with a crew.

FIG. 5 - Several design pictures of a coupemobile. With the axles retracted, the length of the vehicle is only $2.2 \mathrm{~m}$, while the wheelbase is increased by $1 \mathrm{~m}$ while driving. It is possible to enter the trains laterally and to park perpendicular to the pavement.
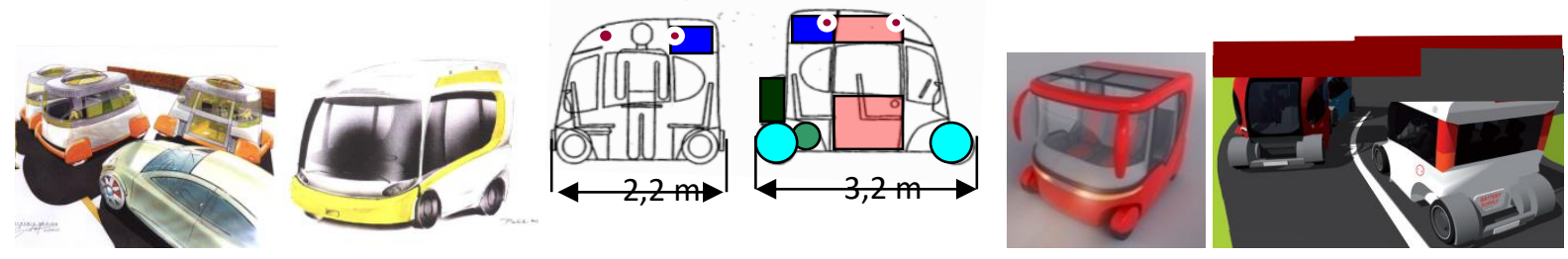

\subsection{INFRASTRUCTURE OF THE COMPLEXTRANS SYSTEM}

The ComplexTrans system does not need any extra roads or railways. However, it would be appropriate, if the railway were to allow travelling speeds of about $200 \mathrm{~km} / \mathrm{h}(160-230 \mathrm{~km} / \mathrm{h})$. Of course, new terminals for interconnecting road and railway networks must be built on the city borders.

Terminals should be located at distances from about 50 to $200 \mathrm{~km}$ near the cities and agglomerations (Fig.6). Terminals can be designed also as semi-terminals (Fig.8) located after cities (relative to the direction of travel), where loading and unloading is done only in one direction. At the beginning of their trip the drivers always have two options - road or railway. Close to big cities, fullterminals will be situated on both ends of cities.

Each platform situated inside a terminal is built as a two-sided, double deck platform (Fig.7), where the lower deck is used for loading and unloading road vehicles and for waiting for cargo transport modules, and the upper deck for boarding and disembarking of passengers.

Loading and unloading platforms are connected to the public road network. Preparatory and waiting parking places for personal and cargo vehicles are situated at the entrance to the terminal, and the sorting and waiting parking for cargo transport modules (distributed to customers outside rush hours) are situated at the exit of the terminal.

FIG.6 - optimal location of one terminal and two half-terminals for not too big cities where two railways and two motorways cross. The driver always has the choice between road or using the ComplexTrans system.

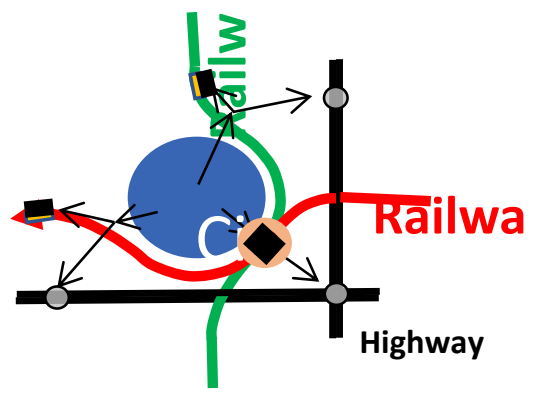


FIG.7 - cross-section through the two-story platform of the ComplexTrans system. The lower deck serves for loading and disloading of passenger cars and waiting freight transport modules. The car crew remains in their coupemobiles during the rail transport as in a rail coupé. The other passengers are transported on the upper deck, where they come from the second floor of the platform by folding doors with stairs located at the ends of the coaches.

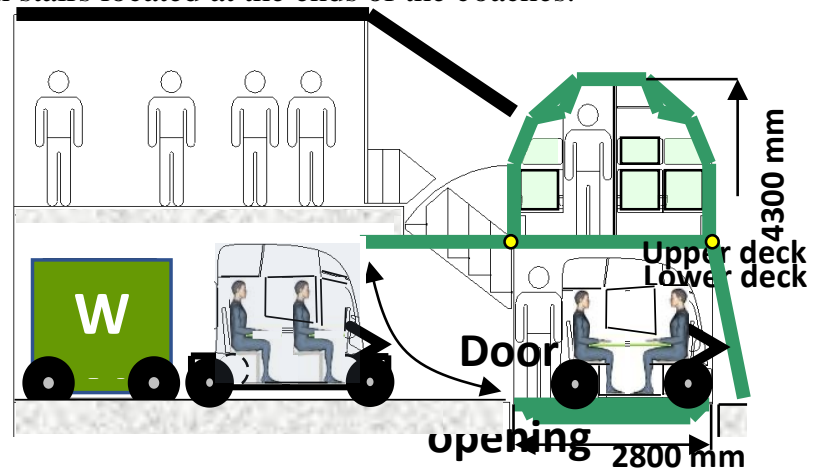

Each terminal (Fig.8) is equipped with several tracks, where separate fast freight railway wagons (or small sets) wait for connection to one of the next ComplexTrans trains, or vice-versa for the final transport to the end customer. Connecting and disconnecting the freight wagons to the ComplexTrans trains completely replaces all manipulations of cargo trains in marshalling yards.

FIG.8 - the half-terminal located behind the city allows loading and unloading in only one direction. It houses several parallel tracks with platforms for loading and unloading. Furthermore, the terminal is equipped with several rails for freight wagons where they are waiting to be connected to the following ComplexTrans trains or to be transported to the final customer. On arrival and departure there are preparation and waiting parking facilities for cars and freight transport modules.

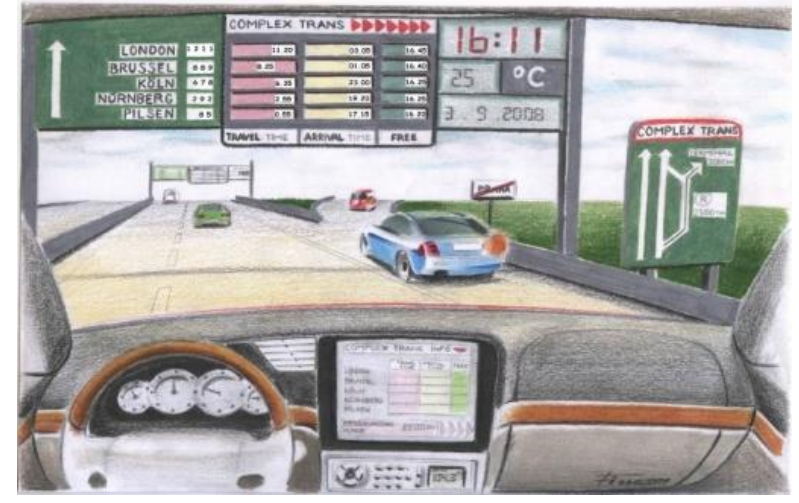


FIG.9 - the information system offers the driver information about the road-distance of the destination and the time of reaching the destination when using the ComplexTrans system. Thus, the driver always has the possibility of making last-minute decisions about the mode of transport.

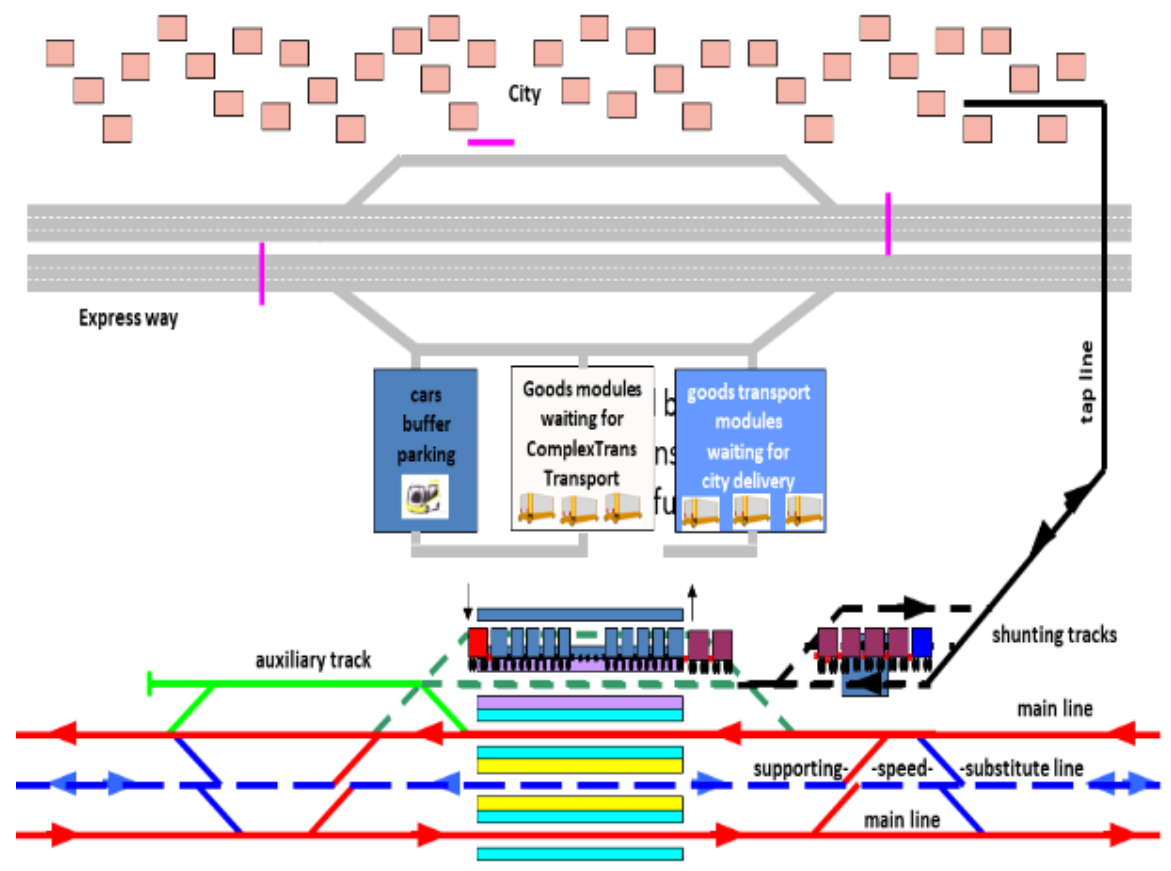

Part of the ComplexTrans infrastructure is an online information and reservation system (Fig.9). The system provides the driver current information about the distance to destination and arrival time via road or railway, to allow the drivers to make their decision at the last moment, and select (and also book) the optimal variant.

The reservation system prefers personal vehicles to waiting cargo modules, unless the goods are transported using the express regime.

Part of the road infrastructure are also lightweight bridges over crossroads for platoons of coupemobiles, new types of parking devices, stops for additional public city transportation, and 'energy centres' for recharging replaceable batteries or replacing batteries with range-extenders.

\subsection{ORGANIZATION AND TIMETABLE OF THE COMPLEXTRANS TRANSPORTATION} SYSTEM

Considering that ComplexTrans trains will transport people, personal cars with passengers, personal and cargo transport modules and freight wagons, they will have enough loads and will travel very frequently.

A ComplexTrans train with 20 double-deck carriages can transport 120 coupemobiles or 60 standard cargo transport modules on the lower deck and about 900 people on the upper deck. If the interval between two next ComplexTrans trains is 5 minutes in each direction, the overall capacity of a double 
track is similar to a highway, where every $2 / 4 / 16$ seconds a personal car/van/truck drives in each direction, and among that a bus every 3 minutes.

The optimal ratio of transported items can be influenced by a suitable tariff policy and maximum loading of the lower deck is guaranteed by constantly arriving personal vehicles and waiting cargo transport modules.

Five minute intervals between trains, or even shorter, are economically feasible.

It also means that ComplexTrans trains will be attractive from a time point of view. If you miss one train, the next will arrive in a moment. Therefore it will be possible to abandon traditional timetables. The departure and arrival of a particular train will not be guaranteed, only the minimum and maximum travel time between two points and the maximum of waiting time for the next train.

For a journey from one city to another you simply board your coupemobile and in the suburbs of your city you decide (based on the current situation) whether to stay on the road or take a ComplexTrans train. Travel expenses will be the same (the price of the transport in the train will be the same as the price of the fuel for the road trip).

The difference will be on the total travel time. For shorter distances up to $100-150 \mathrm{~km}$ in normal conditions the road will be faster. For longer distances the train will be more effective (Fig. 10).

The advantages of transport in ComplexTrans trains are higher safety, possibility to use the time on the trip for other activities (like autonomous ride), and elimination of wear of your road vehicle.

It is very important that during the journey it will be possible to charge the batteries of electromobiles. This supports electromobility, because the maximum range of electric cars becomes independent of the battery capacity.

The batteries can be used at the same time for storing energy from sustainable sources (wind and sun) and from regenerative braking. 
FIG.10 comparing of the ride duration of the ComplexTrans system with other modes of transport - car, high-speed train, aircraft, and up-to-date ways of faster transport (high-speed train with increased velocity, subsonic Boeing Cruiser and Hyperloop). Including one/two nights (the passenger sleeps during their transport in their own car), ComplexTrans is "the fastest" and most comfortable transportation solution up to distance $\approx 1500 \mathrm{~km}$.

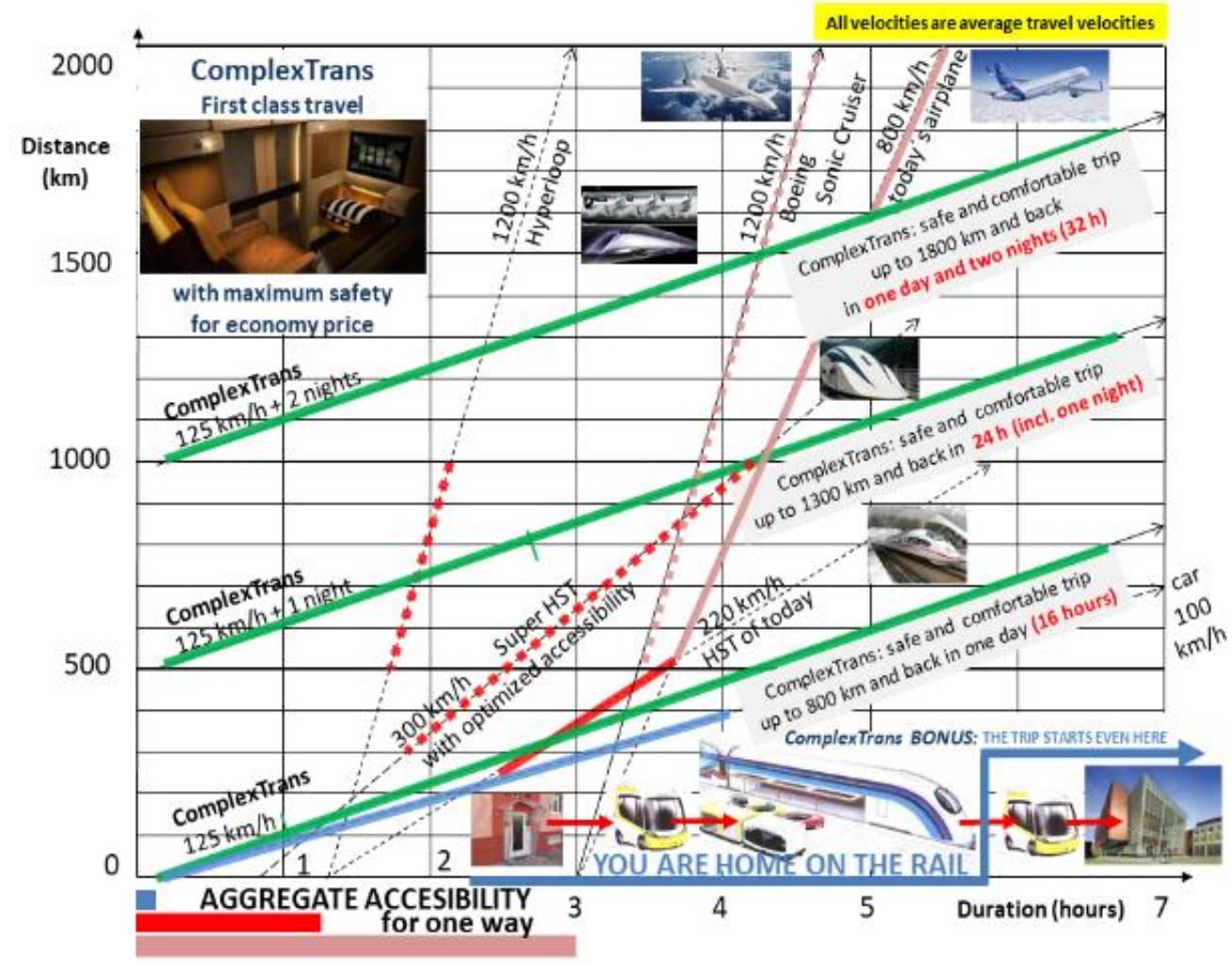

\subsection{ECONOMY OF COMPLEXTRANS COMBINED TRANSPORTATION SYSTEM (SELF-} FINANCING OF RAILWAY)

A standard personal car transported by train needs about $80 \%$ of the energy needed for driving on the road. Because 2 coupemobiles can be transported instead of one standard car, energy savings are about $60 \%$ and energy costs savings are about $75 \%$ (considering various level of tax).

This difference in energy costs creates a potential for covering all other costs of the railway part of the ComplexTrans system - purchasing of vehicles, infrastructure, maintenance and labour costs (Fig.11).

If a coupemobile driver on a train pays only the price equivalent to the price of fuel for a road trip, if the cargo will be transported for the same prices as on roads, and if normal passengers pay less than today, one ComplexTrans train can generate (after energy costs deduction) about 9 mil.€ yearly profit $(10,6 € / \mathrm{km})$. Together with optimal use of infrastructure, the specific infrastructure costs are also reduced (Fig. 12). All this shows that railway transport can become self-financing. A high density of trains and their maximum loading is important for the self-financing of railways. 
An optimum price policy, where prices of transport by ComplexTrans trains are comparable to the price of road transport, together with other benefits - decreasing of wear of private vehicles, time savings and environmental friendliness - can all help.

FIG.11 - the energy and price comparison of rail transport of a conventional car and a coupemobil shows why coupemobiles for transport in the train are much more economical. It is possible to get much more money from one place when transporting coupemobiles instead of common cars.

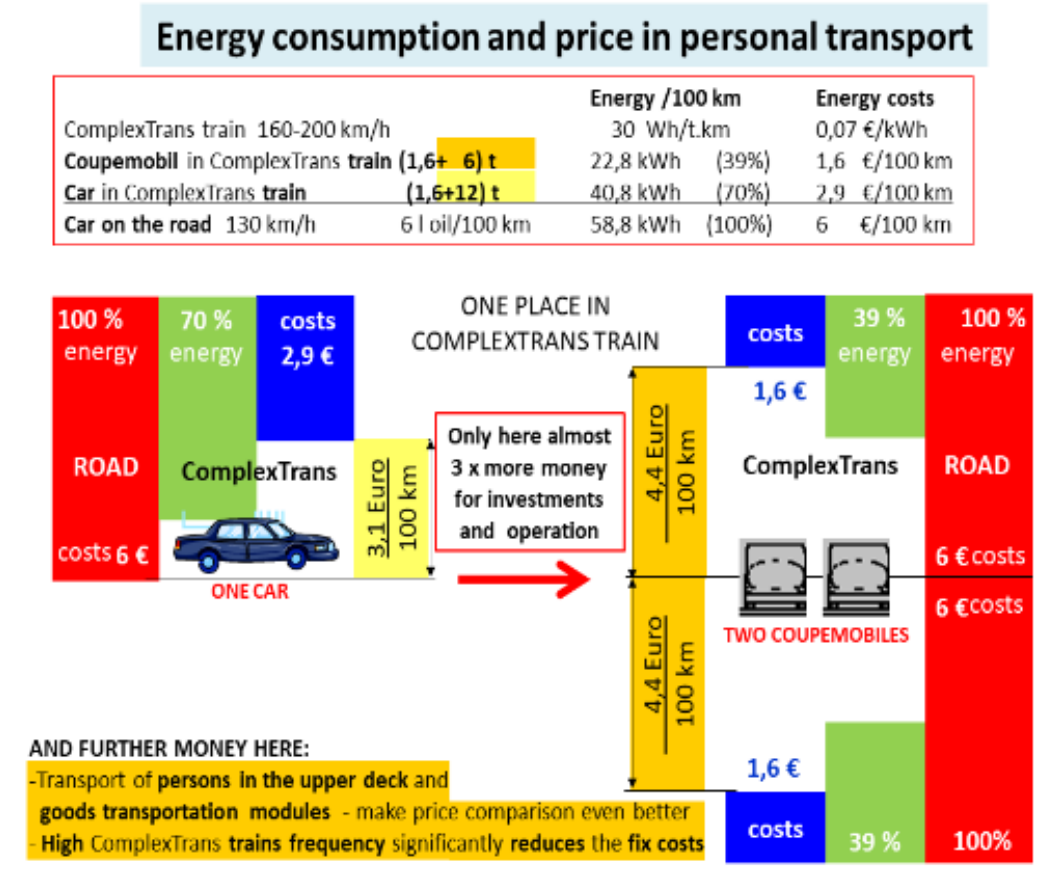

FIG.12 - economic evaluation of ComplexTrans trains. When every car and freight transport module pays for transport on the train as if it were on the road (passenger cars pay for fuel price only), then each ComplexTrans train (locomotive +20 ComplexTrans cars) can obtain (after deducting energy costs) more than $€ 10$ for each kilometer. This profit can be used to cover train purchase and maintenance costs, track maintenance and labor costs.

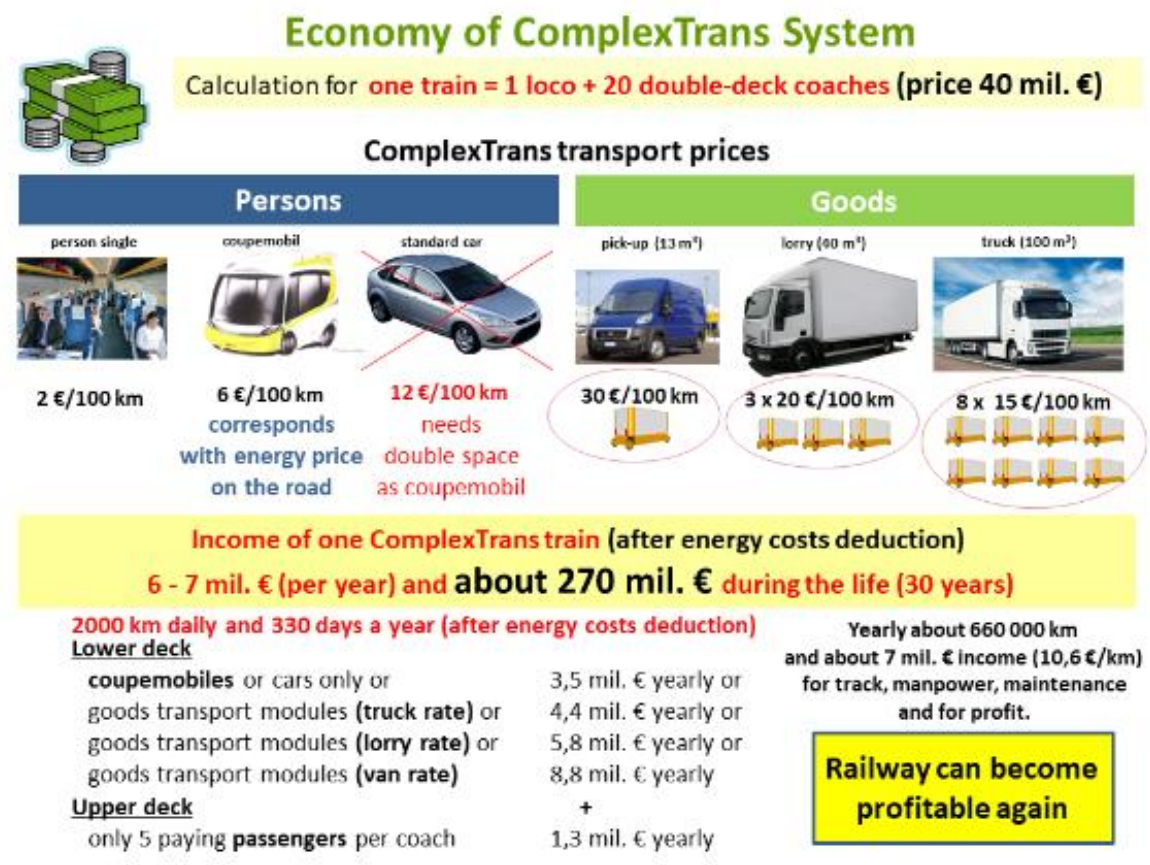




\section{WHAT DOES COMPLEXTRANS BRING TO ROAD TRANSPORT?}

The adaptation of private vehicles to the ComplexTrans system will make them significantly more compact and some of their parts will have new functions and designs. Although some conservative car fans might consider it a disadvantage, this new form of vehicle together with its 'right' dimensions will give vehicles completely new abilities which can improve and enrich road transport. A high-quality designed coupemobile could soon be the most widely spread vehicle on the roads.

\subsection{IN CITIES}

\subsubsection{Space saving parking, new places to park}

The short length of the coupemobile with retracted axles in parking mode is the same as the width of a parking lane. Coupemobiles can park perpendicular to the longitudinal parking lane and double the parking capacity.

Apart from this, compact coupemobiles are equipped with catch points in the roof creating new possibilities for parking in elevated parking lanes above pavements (Fig.13) or in vertical underground or elevated parking silos (Fig.14). Total parking capacity could be tripled at least.

Coupemobiles could in the future be parked on the balconies of new buildings using external elevators (Fig.15). They could be used for different purposes when not travelling and be connected to the electrical network for most of the day.

FIG.13 - thanks to its compact shape and roof catch points, coupemobils can be parked in special parking facilities above the sidewalks.

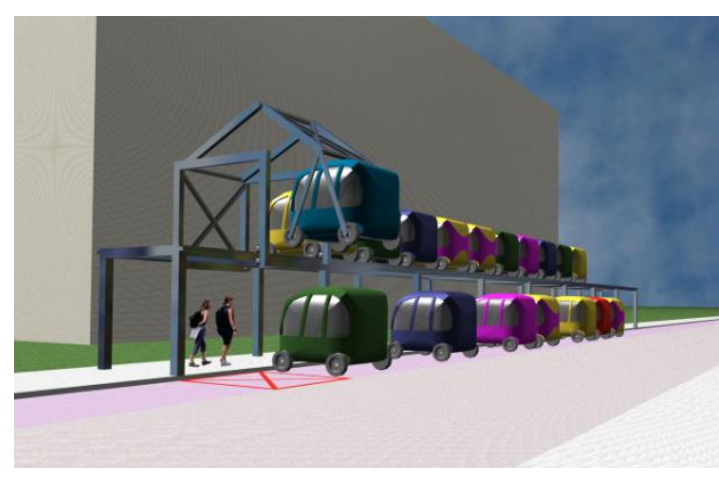

FIG.14 - another way to park a coupemobil will be an overground or underground parking silo (tower).

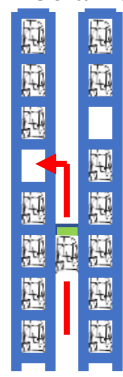


FIG.15 - the multi-storey residential and office buildings will be equipped with balconies for parking of coupemobiles, which will be lifted there by external lifts. This will always ensure a safe parking space and easy loading and unloading. Coupemobiles with all their technologies will be used as an additional study or relaxation room.

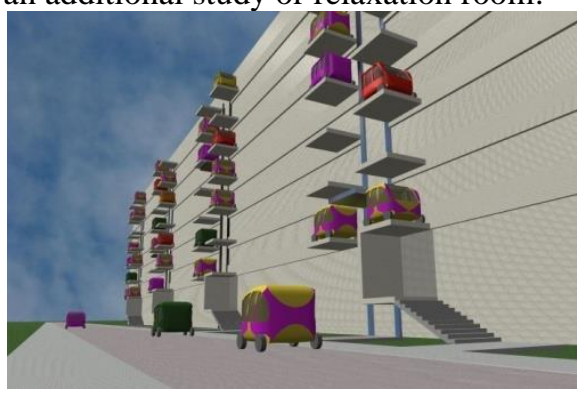

\subsubsection{PLATOONING - ASSEMBLING AND OPERATING SETS OF VEHICLES}

With couplings equipped retractable axles enable the mechanical connection of several vehicles into one set.

Vehicles are connected electronically during the ride (Fig.16) or mechanically in sorting lanes (Fig.17).

Platoons decrease the density of traffic up to by $50 \%$, double the throughput of crossroads, and can use special lightweight bridges for spanning crossroads (Fig.18) to increase traffic flow.

The low air resistance of platoons also saves energy.

FIG.16 - coupemobiles will be able to make electronically tight groups driving in the same direction. This will reduce traffic density and increase transport speed.
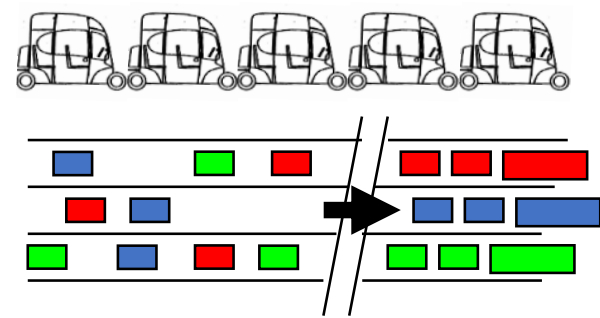

FIG.17 - coupemobiles can also be coupled mechanically using a coupler placed on the extendable axles. For coupling of the coupemobiles with the same direction will be used sorting terminals.

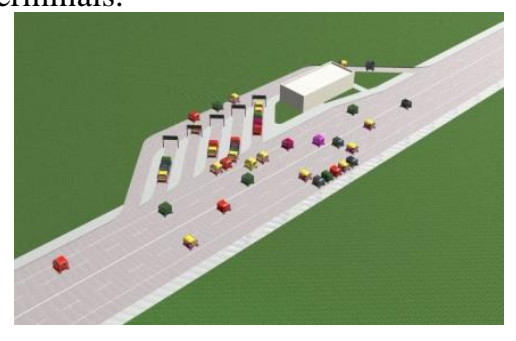

FIG.18 - platoons of coupemobiles will be able to use light junction bridges to increase the driving fluidity.

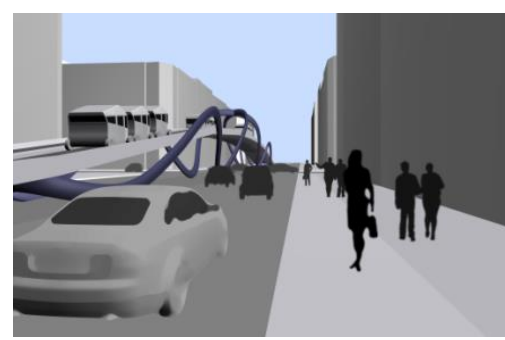

\subsubsection{INCORPORATING PLATOONS INTO PUBLIC TRANSPORT}

Platoons of coupemobiles (from 2 to 5 vehicles) are similar to electrobuses and can offer plenty of free places for registered users of public transport (Fig.19).

Cooperation between coupemobile owners and public transport providers on a contractual basis could create a very comfortable, high capacity transportation system supporting the conventional public transport system especially in rush hours. 
A transport company doesn't need an excessive number of vehicles for public transport and coupemobile owners can be remunerated for their public mode trips.

During trips in the city a transport company on-line organizes ad hoc connection of platoons of coupemobiles going in the same direction at the nearest suitable stop (Fig.20), leads the platoon through the city in the required direction, organizes stops and passengers getting in and out (Fig.21). The platoons are disconnected at the last suitable stop and each coupemobile continues in the private mode to its own destination.

FIG.19 - a platoon consisting of five FIG.20 - a platoon of coupe- mobiles is FIG.21 - an ad hoc platoon (made up of private coupemobiles offers from 20 to formed at the stop, another platoon is just private coupe-mobiles) is temporarily 29 free seats for use in public transport. passing by. included in the public passenger transport (under a contract of owners
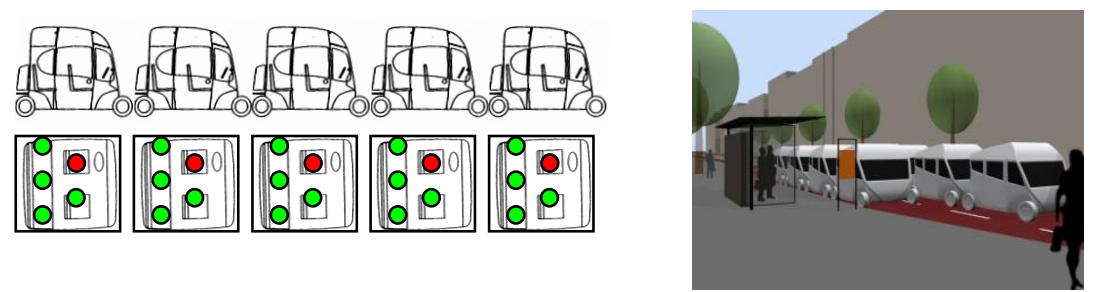
with the carrier)

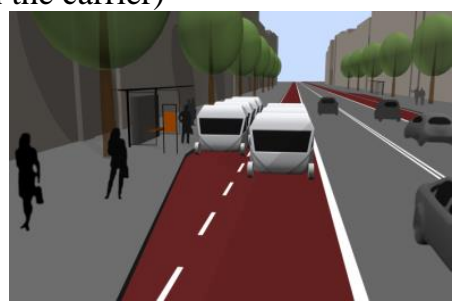

\subsubsection{Cargo transport in cities}

Cargo in cities will be transported primarily by modules for goods transport (Fig.22), which are comparable with vans today (without driver's cab). Transport modules have electrical drive with limited power.

Remote control is used for local manipulation of the transport modules (Fig.22).

Transit of transport modules between customers and terminals is performed on roads in platoons with guiding vehicles (Fig.23) - primarily outside rush hours.

Transport modules wait for train transport or for transport to customers at terminal parking places and on platforms. Priority deliveries can be made anytime without waiting.

FIG.22 - the remote control is used for local handling of the freight transportmodule.

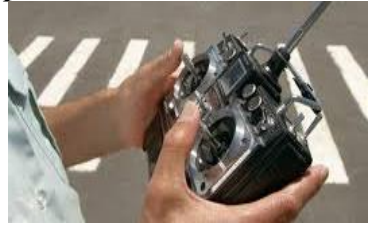

FIG.23 - between the terminal and the customer, the freight transport modules are transported by the guiding vehicle.
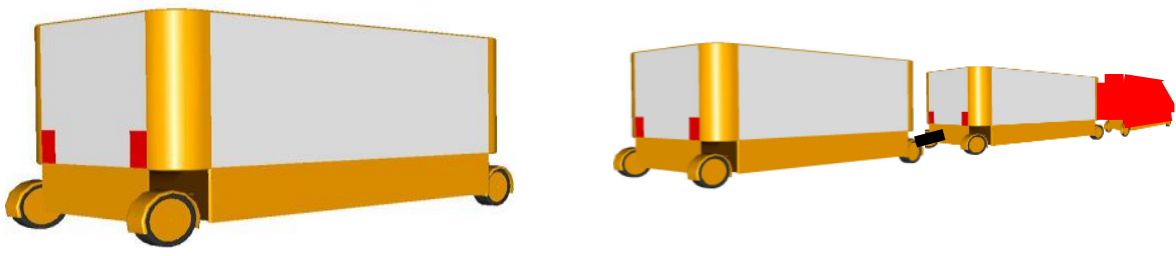


\subsubsection{Reducing traffic density}

Short coupemobiles (length circa $3.2 \mathrm{~m}$ for driving, and only $2.2 \mathrm{~m}$ for parking) save 10-20\% space when driving and up to $50 \%$ or even more when parked).

Space savings are even higher when driving in platoons (more than $50 \%$ ).

Using platoons of coupemobiles in public transportation can reduce the traffic density because the same number of passengers can be transported by fewer vehicles.

Traffic density will be decreased by easier parking place founding.

Traffic density will be decreased also by transporting goods outside rush hours.

Reduction of traffic and parking density by 50 to $75 \%$ can be expected.

\subsection{OUTSIDE THE CITY}

\subsubsection{Energy for long distance trips by electro-mobile in ComplexTrans}

The ComplexTrans system primarily uses electric trains for long distance transport of electromobiles, during which time their traction batteries can be recharged (on or off the train). By the time they reach their destination, the batteries are fully charged.

During long distance road trips, traction batteries are replaced by a 'range-extender', which is an independent source of electric energy (e.g. combustion engine driven electrical generator or hydrogen fuel cell).

After the trip the range-extender is exchanged for a traction battery again.

\subsubsection{Organization of long distance road trips}

Coupemobiles can be organised into platoons on long distance road trips for better use of the time on the trip, more comfort and energy savings. Platoons are led by a driver in the first car, which may be (but doesn't have to be) provided by a professional haulage company.

\section{MORE CONSEQUENCES AND CONTRIBUTIONS OF COMPLEXTRANS}

\subsection{FULL ELECTRIFICATION OF LAND TRANSPORT}

The ability of electrically driven coupemobiles to travel for long distances with lower capacity of traction batteries can significantly contribute to establishing electromobility on roads. The fact that a traction battery is easily accessible from the rear, and it can be replaced anywhere by suitable mobile technology (by a vehicle for distribution and replacement of batteries), can also contribute to this. It is not necessary to build a large recharging infrastructure to increase the range of electromobility.

Because a relatively small traction battery is easy to replace, it is not necessary to make it a part of the vehicle and it can be owned by an energy distributor. The cost of a new battery can be successively 
paid for in energy bills, which will make coupemobiles cheaper and more attractive than cars with combustion engines, and open the way to the full electrification of land transport. It will be further supported by coupemobiles' comfort, parking ability, platooning ability, and use of new infrastructure components.

ComplexTrans will be able to provide almost all land transport on an electrical basis.

\subsection{SUPPORT OF TRANSITION TO SUSTAINABLE SOURCES OF ENERGY}

ComplexTrans enables all road vehicles to be driven by electricity. Vehicles need traction batteries for this. If the majority of road vehicles have traction batteries, the total power input of these batteries will be comparable with the power from all sources of electrical energy.

Because electric vehicles in ComplexTrans will be connected to the electrical network much more often than conventional electro-mobiles (during rail transport, at new types of parking lots and through recharging centres), and the batteries will be owned by electricity distributors, this huge capacity of accumulators can be used for storing energy from renewable energy sources (from solar and wind).

FIG.24 - the ComplexTrans transport network and the electricity network will be interconnected into one mutually supporting and securing system

ENERGY-TRANSPORT-LIFE COOPERATION BY COMPLEXTRANS

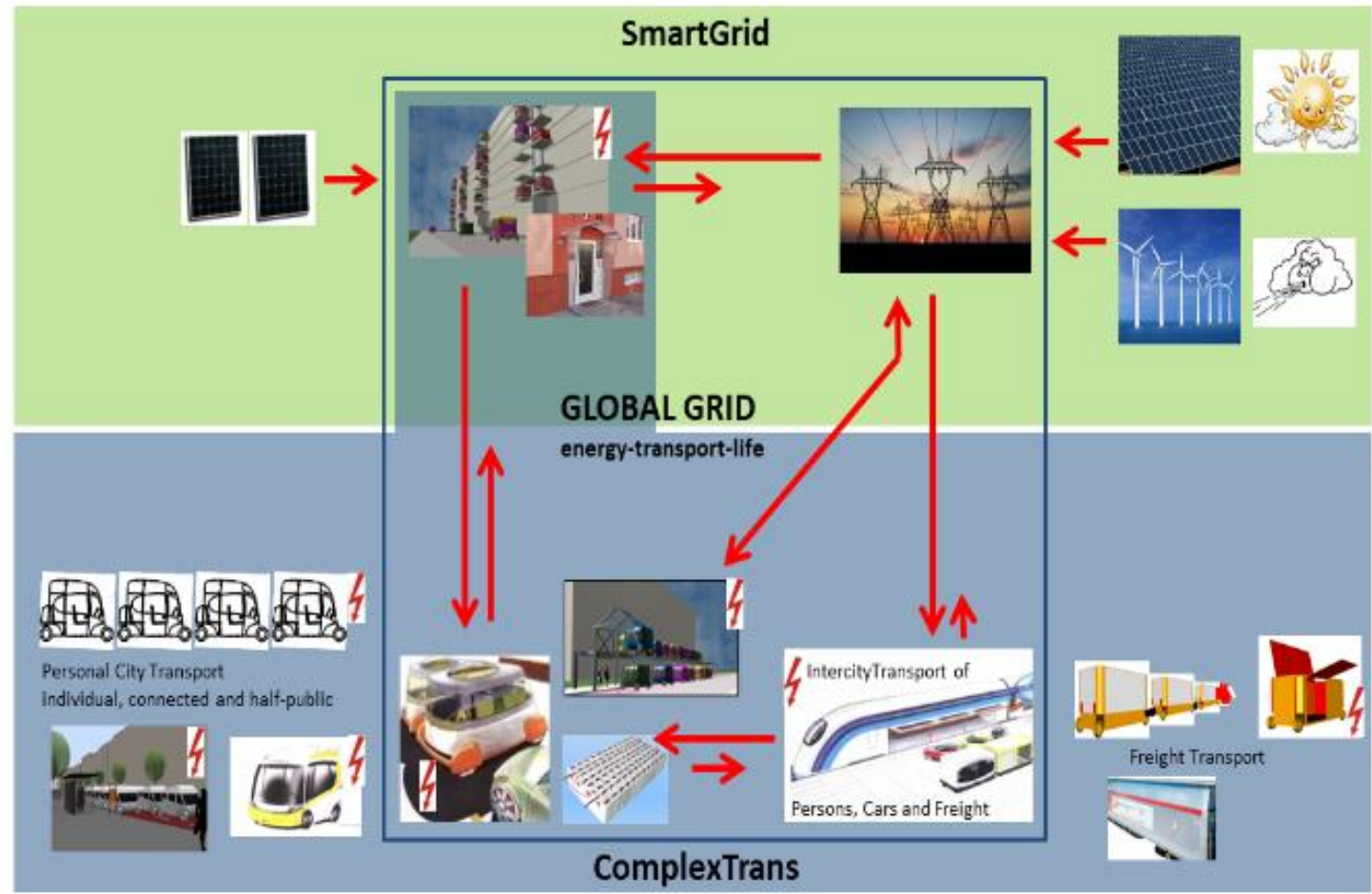




\subsection{INDEPENDENCE OF LAND TRANSPORT FROM CRUDE OIL AND REDUCTION OF CO2} EMISSIONS

ComplexTrans makes crude oil for land transport almost needless if there are enough other energy sources available.

The estimate is that up to $100 \%$ of rail transport and at least $90 \%$ of road transport can be driven by electricity in ComplexTrans system. Only $10 \%$ of road transport will stay dependent on fossil/synthetic fuels or hydrogen.

Nowadays, road and railway transport consume more than $50 \%$ of crude oil. 19)

When including night travelling (passengers are transported to their destination sleeping in their own coupemobile), ComplexTrans is less time demanding than air transport for distances up to $1500 \mathrm{~km}$ (and $1500 \mathrm{~km}$ back) meaning that short continental flights can be replaced by ComplexTrans.

With the full use of ComplexTrans, crude oil consumption can be decreased almost by $50 \%$.

This means also a reduction in the production of circa 6000 million tonnes of $\mathrm{CO} 2$ per year.

\subsection{ENERGY SAVINGS}

Apart from the fact that it doesn't need energy from crude oil, ComplexTrans decreases the energy demands of land transport. During rail transport, a coupemobile can save circa $60 \%$ of energy compared to driving on the road.

Energy savings can be achieved by using platoons, which decrease aerodynamic resistance. Using platoons in public transport also decreases the number of vehicles needed for public transport.

Fewer vehicles on roads and platooning make transport continuous and energy efficient. Energy is saved by easier parking. Energy savings are obtained by better use of the lower decks of ComplexTrans trains and increasing the ratio of passengers in the upper deck.

It can be expected that ComplexTrans will save circa $40 \%$ of energy for transport.

\subsection{AUTONOMOUS DRIVING, CONNECTIVITY, 5G NETWORKS}

Transport of coupemobiles on ComplexTrans trains is equivalent to autonomous driving, where drivers don't need to drive, and can do something else instead.

In contrast to autonomous driving on roads, "autonomous" driving in a ComplexTrans train doesn’t require any demanding technology, 5G-connectivity with other vehicles, etc.

Safe "autonomous" driving on ComplexTrans trains can be arranged simply and quickly. 


\subsection{USING ADVANCED TECHNOLOGIES IN COMPLEXTRANS}

Almost all the currently developing advanced road and railway transport technologies can be implemented in ComplexTrans.

However, ComplexTrans doesn't depend on these technologies and is able to achieve similar (in some directions even better) results without them, too. It is important especially from the point of view of reliability and safety of transport.

Later implementation of progressive technologies (autonomous driving, connectivity, MaaS, carsharing, etc.) will complement ComplexTrans. And also bring time enough for achieving high quality and safety of these advanced technologies.

\subsection{HARDLY MEASURABLE EFFECTS OF THE COMPLEXTRANS SYSTEM}

Apart from measurable values such as trip time, traffic density, safety, energy consumption and $\mathrm{CO} 2$ emissions, ComplexTrans provides other hardly or even non-measurable improvements, e.g.

- better ride comfort and better time use during the trip,

- lower traffic load and higher life-comfort on cities,

- increasing manpower mobility and more social security,

- 'shrinking' of continents by increasing the reach of land transport during one day,

- support of car industry change or

- protection against the spread of coronavirus and other communicable diseases during transport

\section{CONCLUSION}

Although the current development of road and railway transport is separate, the ComplexTrans project shows that it is beneficial to interconnect both types of transport to achieve highly efficient cooperation.

It can be beneficial for both main systems of land transport.

For the railway system, ComplexTrans achieves better use of existing capacities, harmonization of passenger and cargo transport, increased profitability and self-financing ability.

For road transport, ComplexTrans achieves time savings, energy savings, electrification, "autonomous ride" lower costs, higher comfort and more safety.

It is very important that the realization of both systems does not need to be simultaneous and both systems can be developed from ComplexTrans also independently.

However, during their independent development, it is necessary to keep some common rules to allow future interconnection of both systems. 
It provides also benefits to the field of renewable energy sources. Fast development of electromobility on roads and more frequent connections of their traction batteries to the electrical network is a significant possibility for storing energy from renewable sources, which can improve the development of solar and wind power plants.

But the main benefit will go to transported people, who won't need to spend so much time travelling, who will cover further distances in shorter times, when travelling will enjoy the same comforts as at home, and will use their travel time more comfortably and efficiently.

Another profit (for non-transported) people is the reduction of traffic density in cities and more comfortable city-travelling, reduction of air pollution and noise inside and outside cities.

All this sounds very positive, but it requires the implementation of the ComplexTrans system.

There are more ways to start this. It can start with either railways or with roads or both.

These steps can be relatively simple and smooth, it only requires cooperation.

Europe and the European Union can provide very good platform for developing the ComplexTrans land transport system (Fig.25)

FIG.25 ComplexTrans trains will cross Europe and transport people and freight quickly and economically at speeds of about $200 \mathrm{~km} / \mathrm{h}$. Europe will be better connected and the people of Europe will be closer.

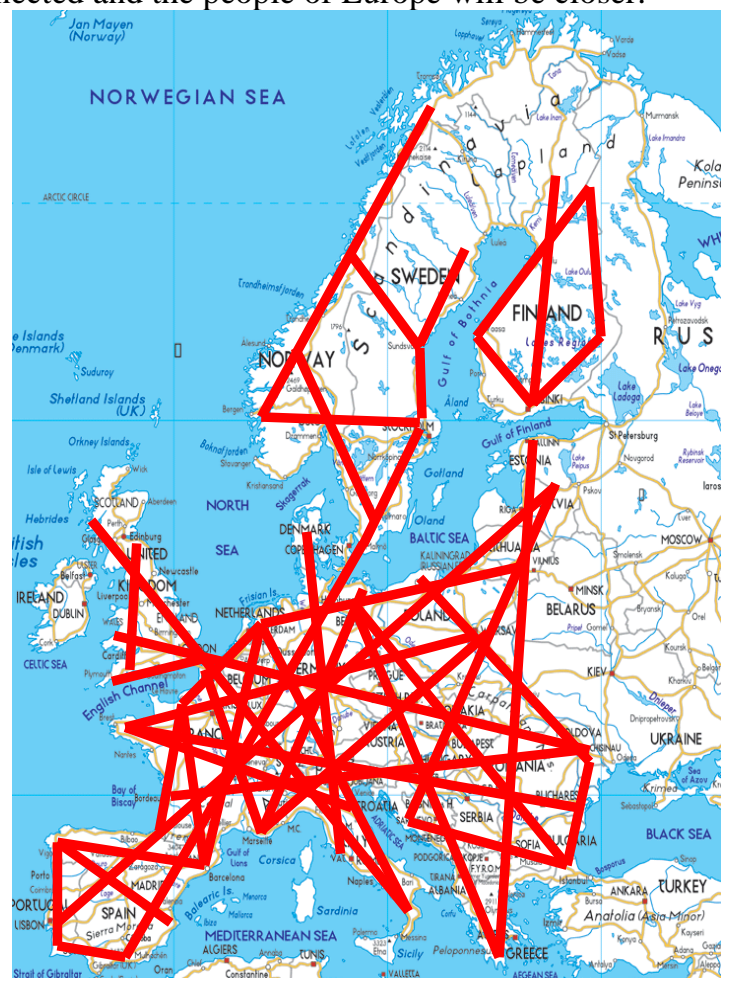

\section{ACKNOWLEGMENT}

This research is partly supported by project SGS-2019-001 


\section{REFERENCES}

Eurostat,2016https://ec.europa.eu/eurostat/statisticsexplained/index.php/Passenger_transport_statistics/d e

Siemenshttps://new.siemens.com/global/en/products/mobility/roadsolutions/electromobility/ehihway.ht $\mathrm{ml}$

Bombardier-https://www.bombardier.com/en/media/newsList/details.bt-20161207-bombardier-primovetechnology-enters-service-on-scan.bombardiercom.html

Wikipedia - https://en.wikipedia.org/wiki/Last_mile_(transportation)

DLR - https://verkehrsforschung.dlr.de/en/projects/ngt-cargo

Wikipedia - https://en.wikipedia.org/wiki/CargoSprinter

Wikipedia - https://en.wikipedia.org/wiki/Rail_freight_transport\#Containerization

Wikipedia - https://en.wikipedia.org/wiki/Roller_container

Wikipedia - https://en.wikipedia.org/wiki/Motorail

Wikipedia - https://en.wikipedia.org/wiki/Rolling_highway

Wikipedia - https://en.wikipedia.org/wiki/Channel_Tunnel

Lohr - https://lohr.fr/lohr-railway-system/the-lohr-system/

CargoBeamer - https://www.youtube.com/watch?v=DbSIAvx3kYk

Riessberger K., 1985, Technical report 85-53, 85-62 TU Graz Eisenbahnwesen

Rinderknecht F.M., 2010, https://www.rinspeed.eu/en/UC_28_concept-car.html,

Siemens, 2018 - https://moodley.at/idsheet/siemens-one4all/

Hofman J., König V., 1999-06-17, Espacenet - patent WO9929552 Railway carriage for joint transportation of passengers and passenger cars and/or transportation modules

Hofman J., König V., 2000-09-08, Espacenet - patent WO0051840 Vehicle for passenger transport on road and rail

IEA Key, 2014, World Energy statistics 